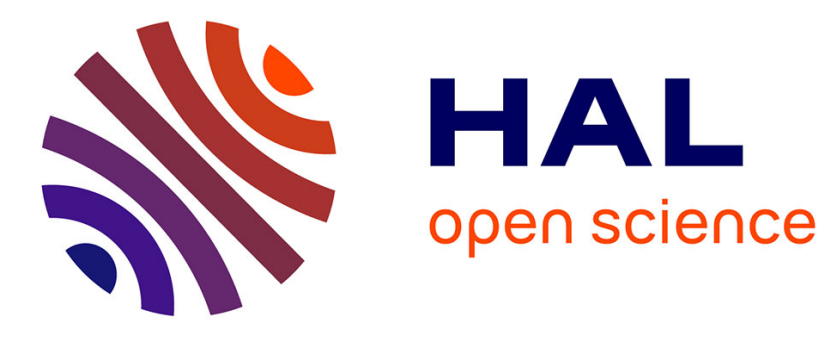

\title{
Night-waking trajectories and associated factors in French preschoolers from the EDEN birth-cohort
}

Eve Reynaud, Anne Forhan, Barbara Heude, Blandine de Lauzon-Guillain, Marie-Aline Charles, Sabine Plancoulaine

\section{- To cite this version:}

Eve Reynaud, Anne Forhan, Barbara Heude, Blandine de Lauzon-Guillain, Marie-Aline Charles, et al.. Night-waking trajectories and associated factors in French preschoolers from the EDEN birth-cohort. Sleep Medicine, 2016, 27-28, pp.59-65. 10.1016/j.sleep.2016.09.008 . hal-02899403

\section{HAL Id: hal-02899403 https://hal.science/hal-02899403}

Submitted on 15 Jul 2020

HAL is a multi-disciplinary open access archive for the deposit and dissemination of scientific research documents, whether they are published or not. The documents may come from teaching and research institutions in France or abroad, or from public or private research centers.
L'archive ouverte pluridisciplinaire HAL, est destinée au dépôt et à la diffusion de documents scientifiques de niveau recherche, publiés ou non, émanant des établissements d'enseignement et de recherche français ou étrangers, des laboratoires publics ou privés. 


\section{Title:}

Night-waking trajectories and associated factors in French preschoolers from the EDEN birth-cohort

\section{Author's name:}

Eve Reynaud ${ }^{\text {a,b }}$, Anne Forhan ${ }^{a}$, Barbara Heude ${ }^{a}$, Blandine de Lauzon-Guillain ${ }^{a}$, Marie-Aline Charles a , and Sabine Plancoulaine ${ }^{a}$

\section{Affiliations:}

a INSERM, UMR1153, Epidemiology and Statistics Sorbonne Paris Cité Research Center (CRESS), early ORigins of Child Health And Development Team (ORCHAD), Villejuif, F-94807 France; ParisDescartes University, Paris, France; (Institution where the work was performed)

${ }^{\mathrm{b}}$ Ecole des Hautes Etudes en Santé Publique (EHESP), Rennes, F-35043 France

\section{Email addresses:}

eve.reynaud@inserm.fr; anne.forhan@inserm.fr; barbara.heude@inserm.fr;

blandine.delauzon@inserm.fr; marie-aline.charles@inserm.fr; sabine.plancoulaine@inserm.fr

\section{Corresponding author:}

Address: Sabine Plancoulaine, INSERM U1153, Team 6 ORCHAD

16 Avenue Paul Vaillant Couturier

94807 Villejuif Cedex, France

Phone: + 33 145-595-109

Email: sabine.plancoulaine@inserm.fr 


\begin{abstract}
Night-waking in preschoolers has been associated with adverse health outcomes in cross sectional studies but is rarely analyzed in a longitudinal setting. Therefore, little is known about the evolution of night-waking in early childhood. The objectives were first, to identify night-waking trajectories in preschoolers and secondly, to examine risk factors associated with those trajectories. Analyses were based on the French birth-cohort study EDEN, which recruited 2002 pregnant women between 2003 and 2006. Data on child's night-waking at age 2, 3 and 5-6 and potential confounders were collected through parental self-reported questionnaires. Night-waking trajectories were computerized using group-based trajectory modeling on 1346 children. We identified two distinct developmental patterns. The "2 to 5 rare night-waking" ( $77 \%$ of the children) and the " 2 to 5 common night-waking". Logistic regressions were performed to identify factors associated with the trajectories. Risk factors for belonging to the "2 to 5 common night-waking" trajectory were exposure to passive smoking at home, daycare in a collective setting, watching television for extended periods, bottle-feeding at night, high emotionality and low shyness. This approach allowed us to identify risk factors associated with nightwaking during a critical age window, and laid the groundwork for identifying children at higher risk of deleterious sleep patterns. Those risk factors are mainly living habits, pointing towards the fact that prevention and intervention programs could be highly beneficial in this population.
\end{abstract}

Key words: child; sleep; arousal; sleep maintenance disorders; group-based trajectory modeling 


\section{INTRODUCTION}

Sleep quantity and patterns greatly change during childhood. Occasional night-waking in preschoolers is part of a normal process of the development and maturation of sleep. At this age, the frequency of night-waking is considered as abnormally high when it exceeds 3 times a week [1,2]. As occasional night-waking is common at such a young age, the effects of sleep disruption may go undetected. About $20 \%$ of pediatricians do not, in fact, ask any questions about sleep during routine consultations [3]. However, night-waking is one of the primary complaints of parents to pediatricians [4] and recent findings suggest that they are associated with aggressive behavior [2], hyperactivity [5], attention problems and impaired reasoning [6].

Most of the studies use a cross-sectional design and they consider sleep disorders in a non-specific manner, among school-aged children. Risk factors that have been associated specifically with nightwaking in preschoolers are maternal depression [7], the child's sleep habits [8] and atopic dermatitis [9]. Only Weinraub et al[10] have analyzed night-waking with a developmental pattern approach. They studied 1200 toddlers ( 3 to 36 months old) and identified two trajectories with the growth mixture modeling method. The first represented children who rarely woke up during the night across the study period, and the second represented children with high night-waking occurrences between 6 and 18 months but similar to the other children thereafter. The analyses of associated factors mainly focused on socioeconomic and demographic variables, along with mother and child psychological and behavioral states. The analyses paid less attention to postnatal exposures such as sleep habits, passive smoking or television viewing, also reported to be associated with sleep quality in children $[11,12]$.

The first objective of our study was to identify night-waking trajectories in children from age 2 to 5-6 in the French EDEN mother-child cohort, using the group-based trajectory modeling method [13], in order to best characterize evolving sleep modalities before children start school. The second objective was to identify risk factors from birth to age 3 years associated with the identified trajectories.

\section{MATERIALS AND METHODS}

\subsection{STUDY SAMPLE}

The EDEN study aims to investigate the pre- and postnatal determinants of child health and development. Details of the EDEN study protocol have been published previously [14]. In short, pregnant women at less than 24 weeks of amenorrhea were recruited between 2003 and 2006, in the university hospitals of Poitiers and Nancy. Those under age 18, unable to give informed consent, functionally illiterate in French, with a history of diabetes, planning on changing address or without social security coverage were excluded from the cohort. Among the 3758 women invited to participate, $2002(53 \%)$ agreed to enroll in the study. Women with multiple pregnancies were excluded. Due to miscarriages, stillbirths and attrition, the number fell to 1899 children enrolled at birth. Written informed consent was obtained twice from parents: at enrolment and after the child's birth. The study was approved by the ethics research committee of Bicêtre Hospital (Comité Consultatif de Protection des Personnes dans la Recherche Biomédicale) and by the Data Protection Authority (Commission Nationale de l'Informatique et des Libertés).

Abbreviations: CES-D, Center of Epidemiologic Studies Depression scale; EAS, Emotionality Activity and Sociability scale; 


\subsection{DATA COLLECTION}

All variables included in our analysis were collected through paper-based self-questionnaires, with the exception of the anthropometric measures, assessed by clinical examination, and the birth term, drawn from medical records.

\subsubsection{Outcome variable}

Parents reported the number of time per week their child woke during the night, at age 2, 3 and 5-6 years. At each time point, and in accordance with the literature, "frequent night-waking" was defined as the child waking every other night or more [1,2], as opposed to "no or occasional night-waking". This binary night-waking repeated measure was used to compute the outcome variable: the " 2 to 5 nightwaking" trajectories. These trajectories were modeled using the "group based trajectory" method described in the statistical analysis section. The reported night-waking were those noticed by parents, meaning that the child signaled being awake. As noted by other authors [15,16], this method, unlike actigraphy, measures the difficulty a child has to fall back to sleep by him/herself. In other words, it accounts for the child's self-soothing capacities and not night-waking per se.

\subsubsection{Socio-economic, socio-demographic and maternal variables}

The household socio-economic and demographic factors, as well as maternal characteristics were collected at inclusion. Household income was divided into three categories: below $€ 1500$ per month, between $€ 1500$ and $€ 3000$ per month, and above $€ 3000$ per month. Education level was also defined in three categories, using the highest level reached by one of the parents: below high-school diploma, high-school diploma, and above. The mother's age at delivery was analyzed as a continuous variable. Single parenting was defined as a mother living without the child's father, another companion, or another adult family member. The mother's depression status during pregnancy was assessed by the French version of the Center of Epidemiologic Studies Depression scale (CES-D), using the cut-off point that has been validated in French Women [17]. Mothers with a CES-D score of 23 or more were considered to present depressive symptoms. We used the mother's nationality (European/ nonEuropean) to take into account potential cultural differences. Ethnicity was not assessed in the EDEN cohort, in accordance with French law and ethics.

\subsubsection{Child's variables}

The child's characteristics, anthropometrics and perinatal exposures were collected at birth from selfreported questionnaires and medical records, including gender, birth order (first/other), ponderal index (defined by birth weight in $\mathrm{kg}$ divided by the cube of birth height in meters), breastfeeding (yes/no) and preterm birth (< 37 weeks of amenorrhea). Temperamental traits, namely emotionality, activity and shyness, were assessed at age 1 using the Emotionality Activity and Sociability scale (EAS) [18]. The child's postnatal environment and health was investigated at age 3. We studied the time spent in front of the television as a continuous variable (hours/day), passive smoking at home ("Does anyone smoke inside child's home several times a month or more?" yes/no), care arrangement (in large collective settings like preschool or day care centers vs. home care) and two sleep habits: falling 
asleep with a parent (yes/no) and bottle feeding at night (yes/no). We also looked at health characteristics when diagnosed by a physician (yes/no): occurrence of ear nose or throat infections, and atopic profile (defined as skin atopy, respiratory or food allergy).

\subsection{STATISTICAL ANALYSIS}

All analyses were performed using SAS (SAS 9.4 SAS institute INC, Cary, NC, USA) ${ }^{\circledR}$.

\subsubsection{Group-based trajectory modeling}

To describe the night-waking patterns of children from age 2 to 5-6, we used the group-based trajectory modeling method (PROC TRAJ procedure) [13]. The method is based on the underlying hypothesis that, within a population, there are inherent groups which evolve according to different patterns. The groups are not directly identifiable or pre-established by sets of characteristics, but statistically determined through each series of responses, using maximum likelihood. The relationship between age and night-waking was modeled by polynomial equations, defining the trajectories. The model selection process is described in supplementary data. Briefly, the most adequate model, regarding the number of groups and the shape of the trajectories, was determined by iterations: different models were computed and then compared using the Bayesian Information Criteria (BIC) and favoring parsimony. The chosen model's quality was verified according to recommended criteria: the average posterior probability $(\geq 0.7)$, the odds of correct classification $(\geq 5)$, and the similarity between the model's estimation of prevalence and the actual prevalence.

Children were included in the trajectory's elaboration if their parents had answered the question regarding night-waking for at least two time points out of three. To verify the robustness of the model, sensitivity analyses were performed: the full procedure was also carried out among children who had complete night-waking data at all three time points as well as separately by gender.

\subsubsection{Study of associated factors}

Children were assigned to the trajectory for which they had the highest probability of belonging. Logistic regressions were then computed to study factors associated with the previously modeled night waking trajectories. We first performed an unadjusted exploratory analysis and then multivariable analyses that included factors previously published as being associated with night-waking between age 2 to 5-6 years and factors that presented a p-value $<0.20$ in our unadjusted analysis. Missing values for studied associated factors represented only $2.8 \%$ of the total data set. Simple imputations (mean value for continuous variables and modal value for categorical ones) were implemented. To assess the role of each exposure group, the multivariable procedure was conducted in four steps. The first model contained socio-economic factors and the mother and child characteristics at birth. The child's postnatal exposures and health, the child's sleep habits and lastly the child's temperament were then successively added to the second, third and fourth models. 


\section{RESULTS}

\subsection{Night-waking trajectories}

Out of the 1899 children enrolled at birth, $1346(71 \%)$ presented two out of three completed time points for night-waking and were included in the trajectory elaboration. Compared to included subjects, non-included subjects $(\mathrm{N}=553)$ had lower parental education levels ( $42 \%$ below high school diploma, against $15 \%(p<0.001)$ ), lower household income (30\% earned below $€ 1500 /$ month, against $11 \%$ $(p<0.001))$, higher maternal depression rates $(14 \%$ of mothers with a CES-D score $\geq 23$, against $7 \%$ $(p<0.001))$, and were more often from non-European countries $(4 \%$ against $1 \%(p<0.001))$. There was no difference between the two populations regarding the child's gender $(p=0.87)$, prematurity status $(p=0.69)$ or birth weight $(p=0.23)$. Frequent night-waking concerned $22 \%(277 / 1277)$ of the selected children at age 2, 26\% (325/1268) at age 3 and 9\% (102/1143) at age 5-6.

The optimal and parsimonious trajectory model to describe night-waking patterns was a two-group model with a linear shape for the first trajectory and quadratic inverted-U shape for the second. The model's average posterior probability was $>0.7$ in all groups; the odds of correct classifications met Nagin's recommendations $(\geq 5)$ for the quadratic trajectory but were slightly under for the linear trajectory, with odds at 3.8 (i.e. medium assignment accuracy). Finally, the estimation of prevalence was sound, as it was very close to the actual prevalence ( $77 \%$ for the first group instead of $78 \%$ ).

The same procedure performed including only children with three completed time points ( $\mathrm{N}=996)$ showed no notable difference regarding the number of groups, the shape of the trajectories or compliance with recommendations. Hence, we chose to include the largest sample size for further analysis. The same procedure was also carried out by gender. Results were again very similar and the analyses were not stratified.

The final trajectories are presented in Figure 1. We subjectively named the two identified trajectories as " 2 to 5 rare night-waking" trajectory representing $77 \%$ of the population and "2 to 5 common nightwaking" trajectory representing $23 \%$ of the population.

\subsection{Factors associated with night-waking trajectories}

Population characteristics are presented in Table 1 and multivariable analyses are reported in Table 2. In the full model (model 4), the risk factors for belonging to the "2 to 5 common night-waking" trajectory were: passive smoking at home, daycare in a collective setting, longer time spent in front of the television, bottle feeding at night, low shyness and high emotionality. The association between low income and night-waking trajectory seen in model 1 was weakened and not significant after adjustment for postnatal environment and sleep habits.

\section{DISCUSSION}

\subsection{Prevalence}

The prevalence of frequent night-waking as declared by parents in our study, at age 2, 3 and 5-6 years respectively, were $22 \%, 26 \%$ and $9 \%$. It is globally consistent with previous findings, with Richman [19] reporting a 20\% prevalence for children between age 1 and 2, Zuckerman et al. [1] a $29 \%$ prevalence for age 3, and Pollock [20] an 11\% prevalence for 5-year-olds. The peak in night- 
waking prevalence observed at age 3 coincides with the onset of nightmares in children [21]. Similar results have been reported in other longitudinal studies [22,23], but not for all [10]. The two trajectories identified in our analysis were very distinct. As Weinraub et al. [10] in their study of younger children (3 to 36 months), we characterized children that rarely signaled their waking up at night, and those who appeared to have difficulties falling back to sleep alone and/or had sleep maintenance insomnia.

\subsection{Socio-economic and demographic factors}

The literature suggests that education and income are associated with sleep quality in teenagers [24] and pre-adolescents [25], but it seems less clear in younger children [7].

In the present study, the fully adjusted model showed no association between night-waking trajectories and parental education. Postnatal environment factors (i.e. passive smoking, care arrangement and television viewing duration) accounted for the association observed primarily between night-waking trajectories and the household income. Further studies are needed to better understand these findings.

Several authors have found in cross-sectional studies that non-Caucasian children had more sleep problems $[26,27]$. As there was no ethnical measure available, and very low national origin diversity in our population, we were not able to investigate ethnic and cultural differences.

\subsection{Perinatal and postnatal environment}

Children exposed to tobacco smoke at home had a higher risk of belonging to the "2 to 5 common night-waking" trajectory. This is consistent with previous publications since passive smoking, as measured in questionnaires, was associated with insomnia in 3-year-olds [28]. Yolton et al. [11], also reported that school-aged boys had a greater risk of sleep anxiety when exposed to passive smoking, measured by serum cotinine levels. The exact mechanism involved is not completely understood. One hypothesis implicating passive smoking as a cause of impaired sleep points to the psychoactive properties of nicotine that stimulate arousal in smokers. Nicotine in particular stimulates the release of dopamine, which enhances attention and arousal in smokers [29].

Television viewing among preschoolers has been associated with reduced sleep duration [30], irregular sleep schedule [31] and increased sleep problems as measured by global scores [12]. However, to the best of our knowledge, it has never been shown to be associated with night-waking specifically in preschoolers. One mechanism underlying this relation may be the potentially violent content of programs viewed before bedtime that may favor nightmare occurrences, especially around age 3 [12].

There was a higher risk of belonging to the "2 to 5 common night-waking" trajectory for children attending large collective care arrangements at age 3 , such as care centers, when compared to children cared for at home. In France, $70 \%$ of the children are in preschool at age 3, and two-thirds enter a collective care arrangement for the first time at this age [32]. However, one might note that the majority of 3-year-old children within collective care arrangement did not belong to the " 2 to 5 common night-waking" trajectory. The relation observed between the latter trajectory and collective care may reflect the stress caused by the resulting modification of daily routine and may only concern children 
who are more sensitive to change in their daily environment. However, children may enter preschool in September only, whereas night-waking information was collected all year round and concerned only the month preceding completion of the questionnaire. Collective care arrangements may have disrupted the children's usual sleep routine by increasing the number of sleep settings and nap-time arrangements and may not always meet recommendations and/or needs [33].

\subsection{Sleep habits, temperament and maternal depression}

Behavioral interventions promoting healthier sleep hygiene are efficient in reducing night-waking occurrences [8], suggesting a causal role of sleep habits. In observational studies, sleep habits have repeatedly been associated with night-waking, including bottle feeding at night and parental presence while falling asleep $[8,34]$. Nevertheless, as often discussed, the association between night-waking and sleep strategies may be bidirectional [35]. Our results show that children who were bottle-fed at night had higher risk of belonging to the "2 to 5 common night-waking" trajectory. Parental presence at bedtime was also associated with night-waking trajectory in bivariate analyses and when controlling for socio-economic factors, mother and child's characteristics, postnatal environment and health; but the association became insignificant after controlling for the child's temperament. Our results, as well as those of Morrell et al. [34], thus suggest that the child's temperament may partly explain the association between sleep hygiene and night-waking. Besides this potential mediating role, the child's temperament appears to have a direct association with night-waking. Difficult temperament has been reported to be associated with night-waking [10,34]. Similarly, our results show that children with more emotionality had higher risk to belong to the 2 to 5 common night-waking trajectory. We found the inverse association for shy children. Shyness in our sample might describe a tendency for children to signal less a difficulty to their parents.

It has also been argued that a fragile psychological state of the parents heightens night-waking occurrences [1], but the direction of this association is complex to determine. Several studies conjecture that at least part of this link is mediated by the sleep strategy employed [7], as depressive mothers are more likely to use inappropriate sleep strategies [36]. We have not found any association between the night-waking trajectories and the maternal depression status as measured at inclusion. However, studies establishing a link between maternal depression and child night-waking [1,7,37], measured depression in postpartum (between 8 and 24 months), simultaneously with night-waking measurements, whereas depressive symptoms were assessed in our study during pregnancy, which might explain the discrepancy.

\subsection{Limitations}

Our study has several limitations. The odds of correct classification in the "2 to 5 rare night-waking" trajectory, grouping $77 \%$ of the children, were slightly below recommendations, meaning a medium degree of accuracy. This may be explained by the broad variability of night-waking signaled by children between age 2 and 5-6. However, a two-trajectory model best fits the data, and the quality of the group-based modeling, as assessed by standard validation criteria, was quite satisfactory as a whole. Parental questionnaires were used to account for night-waking. Thus, the reported night- 
awakenings were those noticed by parents, meaning that the child signaled being awake. i.e. a subjective measure. Video-surveillance would have been an objective mean to differentiate children's self-soothing after sleep awakenings with and without parental awakenings and validate the maternal awakening reports but this was not considered at the time of the study design. Due to the recruitment method, based on voluntary participation in the study, and to the attrition during follow-up, there is over-representation of urban, European, well-educated, high-income households, as well as nondepressed mothers, compared to the national population. We were unable to take into account the potential effect of sleep disordered breathing (about 1.2\% of the general pediatric population according to Bixler et al. [38]) as it has not been assessed in our study. We also could not distinguish severe cases from more moderate health conditions regarding respiratory and dermal allergies and ear-nose-throat infections, which possibly resulted in a lack of association within our study although noted by others as risk factors of night-waking $[9,39]$.

\section{CONCLUSION}

Trajectory analyses give new insight into developmental patterns of night-waking and associated factors. The risk factors were mainly living habits (passive smoking at home, TV watching and sleep habits), thus prevention and intervention programs could be highly beneficial in this population. Temperamental risk factors were also identified. Further studies in larger mother-child cohorts are needed to replicate results. 


\section{ACKNOWLEDGMENTS}

Collaborators : We thank the EDEN mother-child cohort study group (I. Annesi-Maesano, J.Y Bernard, J. Botton, M.A. Charles, P. Dargent-Molina, B. de Lauzon-Guillain, P. Ducimetière, M. de Agostini, B. Foliguet, A. Forhan, X. Fritel, A. Germa, V. Goua, R. Hankard, B. Heude, M. Kaminski, B. Larroque†, N. Lelong, J. Lepeule, G. Magnin, L. Marchand, C. Nabet, F. Pierre, R. Slama, M.J. Saurel-Cubizolles, M. Schweitzer, O. Thiebaugeorges).

We thank all funding sources for the EDEN study: Foundation for medical research (FRM, $\mathrm{n}^{\circ}$ ARS3.29), National Agency for Research (ANR, $n^{\circ} 03-B L A N-0359-01, n^{\circ} 06-S E S T-03501, n^{\circ} 06-S E S T-$ 03502), National Institute for Research in Public health (IRESP: TGIR cohorte santé 2008 program), French Ministry of Health (DGS $n^{\circ}$ CV 05000146), French Ministry of Research, INSERM Bone and Joint Diseases National Research (PRO-A) and Human Nutrition National Research Programs ( $n^{\circ} 4$ NU06G), Paris-Sud University, Nestlé, French National Institute for Population Health Surveillance (InVS, $\mathrm{n}^{\circ}$ 05-PCTT2043), French National Institute for Health Education (INPES, $\mathrm{n}^{\circ}$ 007/05 DAS), the European Union FP7 programs, Diabetes National Research Program, Mutuelle Générale de l'Education Nationale complementary health insurance (MGEN), French national agency for food security, French speaking association for the study of diabetes and metabolism (ALFEDIAM).

\section{Funding Sources}

This research did not receive any specific grant from funding agencies in the public, commercial, or not-for-profit sectors. 


\section{Figure 1}

Title: Night-waking trajectories between age 2 and 5-6 among 1346 children Legend: "2 to 5 rare night-waking" trajectory in grey with triangle marks, "2 to 5 common night-waking" trajectory in black with square marks. Dashed lines represent the $95 \%$ confidence intervals of the trajectory estimations.

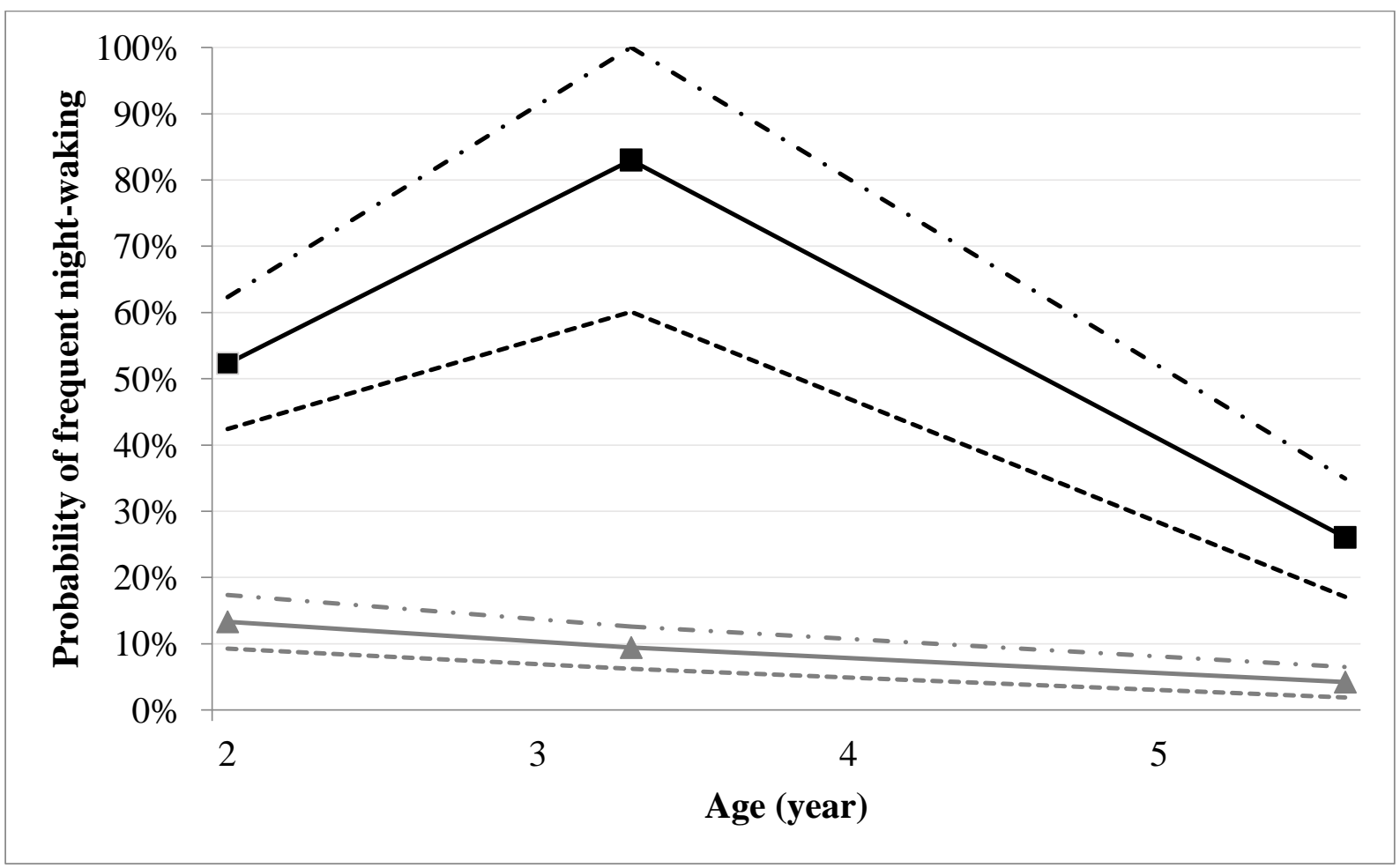


Table 1 Population description on full sample and by night-waking trajectories from age 2 through 5-6 among 1346 French children from the EDEN mother-child cohort.

Data are shown as \%(n) or mean \pm SD

\begin{tabular}{|c|c|c|c|c|c|}
\hline & $\begin{array}{l}\text { Full sample } \\
(n=1346)\end{array}$ & $\begin{array}{c}2 \text { to } 5 \text { rare } \\
\text { night-waking } \\
\text { trajectory } \\
(n=1043)\end{array}$ & $\begin{array}{c}2 \text { to } 5 \\
\text { common } \\
\text { night-waking } \\
\text { trajectory } \\
(\mathrm{n}=303)\end{array}$ & $\begin{array}{c}\text { Bivariate asso } \\
\text { between night- } \\
\text { trajectories } \\
\text { covariate } \\
\left.\text { OR [Cl }{ }_{95 \%}\right]^{i} \\
\end{array}$ & $\begin{array}{l}\text { ciation } \\
\text { waking } \\
\text { and } \\
\text { p } \\
p^{j}\end{array}$ \\
\hline \multicolumn{6}{|l|}{ Frequent night-waking } \\
\hline at age 2.0 years & $20.6 \%(277)$ & & & & \\
\hline at age 3.2 years & $24.1 \%(325)$ & & & & \\
\hline at age 5.6 years & $7.6 \%(102)$ & & & & \\
\hline \multicolumn{6}{|l|}{ Socio-economic factors ${ }^{a}$} \\
\hline Center (, Nancy) & $48,3 \%(650)$ & $50.0 \%(521)$ & $42.6 \%(129)$ & $0.74[0.57-0.96]$ & 0.024 \\
\hline Parental education status & & & & & 0.80 \\
\hline$<$ High school & $14.7 \%(198)$ & $14.8 \%(154)$ & $14.5 \%(44)$ & $1.01[0.69-1.46]$ & \\
\hline High school & $18.8 \%(253)$ & $18.4 \%(192)$ & $20.1 \%(61)$ & $1.12[0.81-1.55]$ & \\
\hline$>$ High school & $66.5 \%(895)$ & $66.8 \%(697)$ & $65.4 \%(198)$ & (reference) & \\
\hline Household income & & & & & 0.026 \\
\hline$<1500 € /$ month & $11.3 \%(152)$ & $10.2 \%(106)$ & $15.2 \%(46)$ & $1.79[1.17-2.74]$ & \\
\hline $1501-3000 € /$ month & $58.3 \%(784)$ & $58.2 \%(607)$ & $58.4 \%(177)$ & $1.20[0.90-1.62]$ & \\
\hline$>3000 € /$ month & $30.5 \%(410)$ & $31.6 \%(330)$ & $26.4 \%(80)$ & (reference) & \\
\hline \multicolumn{6}{|l|}{ Perinatal characteristics } \\
\hline Maternal age ${ }^{b}$ (years) & $30.03 \pm 4.73$ & $30.1 \pm 4.7$ & $29.9 \pm 4.8$ & $0.99[0.97-1.02]$ & 0.54 \\
\hline Maternal depression ${ }^{\mathrm{a}, \mathrm{e}}$ & $6.8 \%(91)$ & $6.6 \%(69)$ & $7.3 \%(22)$ & $1.11[0.67-1.82]$ & 0.69 \\
\hline Child gender (\%(n), Girl) & $47.3 \%(637)$ & $47.1 \%(491)$ & $48.2 \%(146)$ & $1.05[0.81-1.35]$ & 0.73 \\
\hline Child ponderal index $\left(\mathrm{kg} / \mathrm{m}^{3}\right)^{\mathrm{b}}$ & $26.97 \pm 2.74)$ & $26.9 \pm 2.7$ & $27.1 \pm 2.8$ & $1.02[0.97-1.07]$ & 0.43 \\
\hline First child & $46.7 \%(628)$ & $46.6(486)$ & $46.9 \%(142)$ & $1.01[0.78-1.31]$ & 0.93 \\
\hline \multicolumn{6}{|c|}{ Postnatal environment and health $^{d}$} \\
\hline Pre-term birth ${ }^{f}$ & $5.5 \%(74)$ & $5.4 \%(56)$ & $5.9 \%(18)$ & $1.11[0.64-1.92]$ & 0.70 \\
\hline Breastfeeding (months) & $3.38 \pm 3.75$ & $3.35 \pm 3.7$ & $3.46 \pm 3.9$ & $1.01[0.97-1.04]$ & 0.66 \\
\hline Passive smoking at home & $8.8 \%(118)$ & $7.5 \%(78)$ & $13.2 \%(40)$ & $1.88[1.26-2.82]$ & 0.002 \\
\hline Collective care arrangement & $70.2 \%(945)$ & $68.3 \%(712)$ & $76.9 \%(233)$ & $1.55[1.15-2.08]$ & 0.004 \\
\hline Television viewing ( $\mathrm{h} /$ day) & $1.03 \pm 0.75$ & $0.99 \pm 0.71)$ & $1.17 \pm 0.86$ & $1.35[1.16-1.59]$ & $<0.001$ \\
\hline Atopic profile ${ }^{g}$ & $26.2 \%(352)$ & $25.5 \%(266)$ & $28.4 \%(86)$ & $1.16[0.87-1.54]$ & 0.32 \\
\hline Ear nose throat infection & $48.6 \%(654)$ & $47.5 \%(495)$ & $52.5 \%(159)$ & $1.22[0.95-1.58]$ & 0.12 \\
\hline \multicolumn{6}{|l|}{ Sleep habits $^{d}$} \\
\hline $\begin{array}{l}\text { Falling asleep with parental } \\
\text { presence }\end{array}$ & $6.2 \%(83)$ & $5.1 \%(54)$ & $9.6 \%(29)$ & $1.94[1.21-3.10]$ & 0.006 \\
\hline Bottle feeding at night & $19.6 \%(264)$ & $18.0 \%(188)$ & $25.1 \%(76)$ & $1.52[1.12-2.06]$ & 0.007 \\
\hline \multicolumn{6}{|l|}{ Temperament $^{c}$} \\
\hline Activity $^{h}$ & $3.54 \pm 0.48$ & $3.52(0.48)$ & $3.58(0.47)$ & $1.27[0.97-1.67]$ & 0.086 \\
\hline Shyness $^{h}$ & $2.08 \pm 0.56$ & $2.09(0.56)$ & $2.02(0.56)$ & $0.79[0.63-1.00]$ & 0.048 \\
\hline Emotionality $^{\mathrm{h}}$ & $2.77 \pm 0.69$ & $2.75(0.69)$ & $2.84(0.68)$ & $1.20[1.00-1.45]$ & 0.049 \\
\hline
\end{tabular}

${ }^{\mathrm{a}}$ Measured during pregnancy, ${ }^{\mathrm{b}}$ Measured at birth, ${ }^{\mathrm{c}}$ Measured at age 1 year, ${ }^{\mathrm{d}}$ Measured at age 3 years, ${ }^{\mathrm{e}}$ Center of Epidemiologic Studies Depression scale score inferior to $23,{ }^{f}$ inferior to 37 weeks of amenorrhea, ${ }^{g}$ Diagnosed skin atopy, respiratory or food allergy, ${ }^{\mathrm{h}}$ Emotionality Activity and Sociability scale (EAS). Score range 0 to 5 , a higher score indicates more activity, shyness or emotionality ${ }^{\mathrm{i}}$ Odd ratio and $95 \%$ confidence interval, ${ }^{\mathrm{j}} \mathrm{p}$-value 
Table 2 Multivariable analyses of factors associated with night-waking trajectories from age 2 through 5-6 and covariates among 1346 French children from the EDEN birth cohort

\begin{tabular}{|c|c|c|c|c|c|c|c|c|}
\hline \multirow{2}{*}{$N=1346$} & \multicolumn{2}{|l|}{ Model 1} & \multicolumn{2}{|l|}{ Model 2} & \multicolumn{2}{|l|}{ Model 3} & \multicolumn{2}{|l|}{ Model 4} \\
\hline & $\mathrm{OR}\left[\mathrm{Cl}_{95 \%}\right]^{\prime}$ & $p^{J}$ & OR [Cl95\%] & $p$ & OR $\left[\mathrm{Cl}_{95 \%}\right]$ & $p$ & $\mathrm{OR}\left[\mathrm{Cl}_{95 \%}\right]$ & $p$ \\
\hline \multicolumn{9}{|l|}{ Socio-economic factors $^{a}$} \\
\hline Center (Nancy) & $0.73[0.56-0.96]$ & 0.026 & $0.73[0.55-0.97]$ & 0.030 & $0.72[0.54-0.95]$ & 0.021 & $0.70[0.52-0.93]$ & 0.013 \\
\hline Parental education status & & 0.60 & & 0.26 & & 0.13 & & 0.12 \\
\hline$<$ High school & $0.81[0.54-1.22]$ & & $0.70[0.46-1.07]$ & & $0.64[0.42-0.99]$ & & $0.64[0.42-0.98]$ & \\
\hline High school & 0.97 [0.69-1.38] & & 0.93 [0.65-1.33] & & 0.90 [0.63-1.28] & & $0.91[0.64-1.30]$ & \\
\hline Household income ( $€ /$ month) & (RETETERL) & 0.038 & 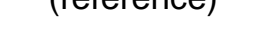 & 0.15 & (reterence) & 0.23 & & 0.24 \\
\hline$<1500 € /$ month & $1.84[1.15-2.94]$ & & $1.61[0.99-2.63]$ & & $1.54[0.94-2.52]$ & & $1.53[0.93-2.51]$ & \\
\hline $1501-3000 € /$ month & 1.19 [0.87-1.63] & & 1.12 [0.81-1.55] & & $1.13[0.82-1.56]$ & & $1.12[0.81-1.55]$ & \\
\hline$>3000 € /$ month & (reference) & & (reference) & & (reference) & & (reference) & \\
\hline \multicolumn{9}{|l|}{ Perinatal characteristics ${ }^{1}$} \\
\hline Maternal depression ${ }^{\mathrm{a}, \mathrm{e}}$ & $1.07[0.65-1.77]$ & 0.79 & $1.06[0.63-1.76]$ & 0.84 & $1.05[0.63-1.76]$ & 0.84 & $1.03[0.61-1.72]$ & 0.92 \\
\hline Child gender (Girl) & $1.08[0.83-1.40]$ & 0.57 & $1.08[0.83-1.40]$ & 0.59 & $1.06[0.81-1.38]$ & 0.68 & $1.10[0.85-1.44]$ & 0.47 \\
\hline Child ponderal index $\left(\mathrm{kg} / \mathrm{m}^{3}\right)^{\mathrm{b}}$ & $1.04[0.99-1.09]$ & 0.16 & $1.04[0.99-1.09]$ & 0.12 & $1.04[0.99-1.10]$ & 0.11 & $1.05[0.99-110]$ & 0.087 \\
\hline First child & $0.97[0.74-1.26]$ & 0.80 & $0.95[0.73-1.25]$ & 0.73 & $0.94[0.72-1.23]$ & 0.66 & $0.89[0.68-117]$ & 0.411 \\
\hline \multicolumn{9}{|l|}{ Postnatal environment and Health ${ }^{a}$} \\
\hline Passive smoking at home & & & 1.65 [1.07-2.55] & 0.023 & $1.64[1.06-2.55]$ & 0.027 & $1.56[1.00-2.44]$ & 0.048 \\
\hline Collective care arrangement & & & $1.49[1.09-2.02]$ & 0.011 & $1.51[1.11-2.05]$ & 0.009 & $1.51[1.11-2.06]$ & 0.009 \\
\hline Television viewing & & & $1.38[1.17-1.62]$ & $<0.001$ & $1.35[1.14-1.60]$ & $<0.001$ & $1.33[1.13-1.58]$ & 0.001 \\
\hline Atopic profile ${ }^{\dagger}$ & & & $1.09[0.81-1.46]$ & 0.57 & $1.07[0.80-1.44]$ & 0.66 & $1.08[0.81-1.46]$ & 0.60 \\
\hline Ear nose throat infection & & & $1.12[0.86-1.46]$ & 0.39 & $1.10[0.85-1.44]$ & 0.47 & $1.11[0.85-1.45]$ & 0.45 \\
\hline \multicolumn{9}{|l|}{ Sleep habits ${ }^{\text {a }}$} \\
\hline Falling asleep with parental presence & & & & & $1.65[1.00-2.72]$ & 0.050 & $1.59[0.96-2.63]$ & 0.069 \\
\hline Bottle feeding at night & & & & & $1.46[1.07-2.01]$ & 0.019 & $1.45[1.06-2.00]$ & 0.022 \\
\hline \multicolumn{9}{|l|}{ Temperament $^{\mathrm{c}}$} \\
\hline Activity $^{\mathrm{h}}$ & & & & & & & $1.17[0.88-1.57]$ & 0.284 \\
\hline Shyness $^{n}$ & & & & & & & $0.76[0.59-0.98]$ & 0.031 \\
\hline Emotionality $^{\mathrm{h}}$ & & & & & & & $1.22[1.00-1.49]$ & 0.049 \\
\hline
\end{tabular}

${ }^{\mathrm{a}}$ Measured during pregnancy, ${ }^{\mathrm{b}}$ Measured at birth, ${ }^{\mathrm{c}}$ Measured at age 1 year, ${ }^{\mathrm{d}}$ Measured at age 3 years

${ }^{e}$ Center of Epidemiologic Studies Depression scale score inferior to 23

${ }^{f}$ Diagnosed skin atopy, respiratory or food allergy,

${ }^{g}$ Emotionality Activity and Sociability scale (EAS). Score range 0 to 5, a higher score indicates more activity, shyness or emotionality

${ }^{\mathrm{h}}$ Odd ratio and $95 \%$ confidence interval, ${ }^{i} \mathrm{p}$-value 


\section{REFERENCES}

[1] Zuckerman B, Stevenson J, Bailey V. Sleep Problems in Early Childhood: Continuities, Predictive Factors, and Behavioral Correlates. Pediatrics 1987;80:664-71.

[2] Shang C-Y, Gau SS-F, Soong W-T. Association between childhood sleep problems and perinatal factors, parental mental distress and behavioral problems. J Sleep Res 2006;15:63-73. doi:10.1111/j.1365-2869.2006.00492.x.

[3] Owens JA. The practice of pediatric sleep medicine: results of a community survey. Pediatrics 2001;108:E51.

[4] Anders TF, Eiben LA. Pediatric sleep disorders: a review of the past 10 years. J Am Acad Child Psy 1997;36:9-20. doi:10.1097/00004583-199701000-00012.

[5] Wang G, Xu G, Liu Z, Lu N, Ma R, Zhang E. Sleep patterns and sleep disturbances among Chinese school-aged children: Prevalence and associated factors. Sleep Med 2013;14:45-52. doi:10.1016/j.sleep.2012.09.022.

[6] Bruni O, Kohler M, Novelli L, Kennedy D, Lushington K, Martin J, et al. The role of NREM sleep instability in child cognitive performance. Sleep 2012;35:649-56. doi:10.5665/sleep.1824.

[7] Teti DM, Crosby B. Maternal depressive symptoms, dysfunctional cognitions, and infant night waking: the role of maternal nighttime behavior. Child Dev 2012;83:939-53. doi:10.1111/j.14678624.2012.01760.x.

[8] Mindell JA, Kuhn B, Lewin DS, Meltzer LJ, Sadeh A, American Academy of Sleep Medicine. Behavioral treatment of bedtime problems and night wakings in infants and young children. Sleep 2006;29:1263-76.

[9] Anuntaseree W, Sangsupawanich P, Osmond C, Mo-Suwan L, Vasiknanonte P, Choprapawon C. Sleep quality in infants with atopic dermatitis: a community-based, birth cohort study. Asian Pac J Allergy Immunol 2012;30:26-31.

[10] Weinraub M, Bender RH, Friedman SL, Susman EJ, Knoke B, Bradley R, et al. Patterns of developmental change in infants' nighttime sleep awakenings from 6 through 36 months of age. Dev Psychol 2012;48:1511-28. doi:10.1037/a0027680.

[11] Yolton K, Xu Y, Khoury J, Succop P, Lanphear B, Beebe DW, et al. Associations between secondhand smoke exposure and sleep patterns in children. Pediatrics 2010;125:e261-268. doi:10.1542/peds.2009-0690.

[12] Garrison MM, Liekweg K, Christakis DA. Media use and child sleep: the impact of content, timing, and environment. Pediatrics 2011;128:29-35. doi:10.1542/peds.2010-3304.

[13] Nagin D. Group-based modeling of development. Cambridge, Mass.: Harvard University Press; 2005.

[14] Heude B, Forhan A, Slama R, Douhaud L, Bedel S, Saurel-Cubizolles M-J, et al. Cohort Profile: The EDEN mother-child cohort on the prenatal and early postnatal determinants of child health and development. Int J Epidemiol 2015. doi:10.1093/ije/dyv151.

[15] Gradisar M, Jackson K, Spurrier NJ, Gibson J, Whitham J, Williams AS, et al. Behavioral Interventions for Infant Sleep Problems: A Randomized Controlled Trial. Pediatrics 2016;137. doi:10.1542/peds.2015-1486.

[16] Kushnir J, Sadeh A. Correspondence between reported and actigraphic sleep measures in preschool children: the role of a clinical context. J Clin Sleep Med 2013;9:1147-51. doi:10.5664/jcsm.3154.

[17] Fuhrer R, Rouillon F. La version française de l'échelle CES-D (Center for Epidemiologic StudiesDepression Scale). Description et traduction de l'échelle d'auto-évaluation. Psychiatr Psychobiol 1989:163-6.

[18] Buss A, Plomin R. Temperament: Early developing personality traits. Lawrence Erlbaum; 2008.

[19] Richman N. Sleep problems in young children. Arch Dis Child 1981;56:491-3.

[20] Pollock Jl. Night-waking at Five Years of Age: Predictors and Prognosis. J Child Psychol Psychiatry 1994;35:699-708. doi:10.1111/j.1469-7610.1994.tb01215.x.

[21] American academy of Sleep Medicine. The International Classification of Sleep Disorders: Diagnostic \& Coding Manual. Revised edition. Rochester, MN: Amer Academy of Sleep Medicine; 1997.

[22] Acebo C, Sadeh A, Seifer R, Tzischinsky O, Hafer A, Carskadon MA. Sleep/wake patterns derived from activity monitoring and maternal report for healthy 1 - to 5 -year-old children. Sleep 2005;28:1568-77.

[23] Blair PS, Humphreys JS, Gringras P, Taheri S, Scott N, Emond A, et al. Childhood sleep duration and associated demographic characteristics in an English cohort. Sleep 2012;35:353 60. doi:10.5665/sleep.1694. 
[24] Marco CA, Wolfson AR, Sparling M, Azuaje A. Family socioeconomic status and sleep patterns of young adolescents. Behav Sleep Med 2011;10:70-80. doi:10.1080/15402002.2012.636298.

[25] El-Sheikh M, Bagley EJ, Keiley M, Elmore-Staton L, Chen E, Buckhalt JA. Economic adversity and children's sleep problems: multiple indicators and moderation of effects. Health Psychol 2013;32:849-59. doi:10.1037/a0030413.

[26] Byars KC, Yolton K, Rausch J, Lanphear B, Beebe DW. Prevalence, patterns, and persistence of sleep problems in the first 3 years of life. Pediatrics 2012;129:e276-284. doi:10.1542/peds.2011-0372.

[27] Nevarez MD, Rifas-Shiman SL, Kleinman KP, Gillman MW, Taveras EM. Associations of early life risk factors with infant sleep duration. Acad Pediatr 2010;10:187-93. doi:10.1016/j.acap.2010.01.007.

[28] Johansson A, Ludvigsson J, Hermansson G. Adverse health effects related to tobacco smoke exposure in a cohort of three-year olds. Acta Pædiatrica 2008;97:354-7. doi:10.1111/j.16512227.2007.00619.x.

[29] Domino EF. Effects of tobacco smoking on electroencephalographic, auditory evoked and event related potentials. Brain Cogn 2003;53:66-74.

[30] Cespedes EM, Gillman MW, Kleinman K, Rifas-Shiman SL, Redline S, Taveras EM. Television Viewing, Bedroom Television, and Sleep Duration From Infancy to Mid-Childhood. Pediatrics 2014;133:e1163-71. doi:10.1542/peds.2013-3998.

[31] Thompson DA, Christakis DA. The association between television viewing and irregular sleep schedules among children less than 3 years of age. Pediatrics 2005;116:851-6. doi:10.1542/peds.2004-2788.

[32] Le Bouteillec N, Kandil L, Solaz A. Who are the children enrolled in French daycare centers? Popul Soc - Mon Bull Fr Natl Inst Demogr Stud 2014:1-4.

[33] Benjamin Neelon SE, Duffey K, Slining MM. Regulations to promote healthy sleep practices in child care. Pediatrics 2014;134:1167-74. doi:10.1542/peds.2014-0578.

[34] Morrell J, Steele H. The role of attachment security, temperament, maternal perception, and care-giving behavior in persistent infant sleeping problems. Infant Ment Health J 2003;24:44768. doi:10.1002/imhj.10072.

[35] Sadeh A, Tikotzky L, Scher A. Parenting and infant sleep. Sleep Med Rev 2010;14:89-96. doi:10.1016/j.smrv.2009.05.003.

[36] Reid GJ, Hong RY, Wade TJ. The relation between common sleep problems and emotional and behavioral problems among 2- and 3-year-olds in the context of known risk factors for psychopathology. J Sleep Res 2009;18:49-59. doi:10.1111/j.1365-2869.2008.00692.x.

[37] Armstrong K, O'donnell H, McCALLUM R, Dadds M. Childhood sleep problems: Association with prenatal factors and maternal distress/depression. J Paediatr Child Health 1998;34:263-266. doi:10.1046/j.1440-1754.1998.00214.x.

[38] Bixler EO, Vgontzas AN, Lin H-M, Liao D, Calhoun S, Vela-Bueno A, et al. Sleep disordered breathing in children in a general population sample: prevalence and risk factors. Sleep 2009;32:731-6.

[39] Ryborg CT, Søndergaard J, Lous J, Munck A, Larsen PV, Thomsen JL. Associations between symptoms, clinical findings and the short-term prognosis among children with otitis media: a cohort study. Int J Pediatr Otorhinolaryngol 2013;77:210-5. doi:10.1016/j.jporl.2012.10.023. 